\title{
Teaching your first political science course
}

\author{
Dominik Stecula \\ Annenberg Public Policy Center, University of Pennsylvania \\ dominik.stecula@appc.upenn.edu \\ I am grateful to Allen Sens, Fred Cutler, Trevor Thrall, Charles Breton, Eric Merkley, Steve \\ Weldon, and Gyuang-Ho Jeong for their help and advice with my first course
}

August 3, 2018

In the summer of 2017, I've had the pleasure of developing, and teaching, my very first course in political science, on the topic of Media and Politics. It was an upper level course, condensed to 6 weeks of instruction with two, three-hour lectures each week. There were a total of 60 students in the course. Since then, I got the opportunity to teach it again, slightly revised, in the summer of 2018, at Simon Fraser University, with just under 30 students. It was also on the condensed, summer schedule. Neither time did I have a TA or any grading help, which seems to be a standard practice in most departments.

In the process of preparing for the course, developing my syllabus, lecture slides and lesson plans, I utilized help from friends and colleagues, and consulted several resources online, but there was no single place (to the best of my knowledge) where one could get a solid overview of how to go about preparing for your very first class. This brief paper is my attempt to provide a useful piece of advice on that front from someone with no teaching experience except several semesters of Teaching Assistantships. This advice will not apply verbatim to every type of course at every department, but I hope that it is at least somewhat useful to everyone. 


\section{COURSE DESCRIPTION AND LEARNING OBJECTIVES}

Before you begin to think of how to break out your course into substantive themes, think more broadly about what it is that you want to accomplish by the time the semester ends. It might sound silly, or obvious, but you should develop a brief list of broad learning objectives that your course aims to focus on. Try to use action verbs here and do not go crazy - more than five goals is likely too much and unrealistic. Furthermore, you want the goals to be thematic. It might sound like this is of secondary importance, but students really appreciate a course that really makes sense and aim to achieve specific things. If what you do each week is not fully related to your learning objectives, you're in trouble. Use these learning objectives to then develop a brief overview of the course and let your goals guide the process of putting together the reading list and assignments. Lastly, you want these to make sense to your students, and you want to make sure that the course actually addresses these objectives.

My learning objectives were the following:A major objective of this course is to learn to think in systematic and nuanced ways about the media's coverage of the political world instead of relying on grotesque simplifications that pervade public thinking about the media and their role in politics. We will carefully examine what the media do well and where they fail. The key objectives are:

1. Develop understanding of major theoretical approaches in political communications

2. Demonstrate the ability to apply theoretical knowledge to current events

3. Synthesize academic literature into concise arguments

4. Evaluate the quality of evidence in empirical research (how do we know what we know about the media?)

5. Critique the quality of information in the news environment

Every topic you cover and readings and homework you assign should tie back to one or several of these objectives. That way students know exactly what the purpose of every component of the course is.

So, what should your objectives be? You should use Bloom's Taxonomy of learning as a guide. 


\section{Bloom's Taxonomy}

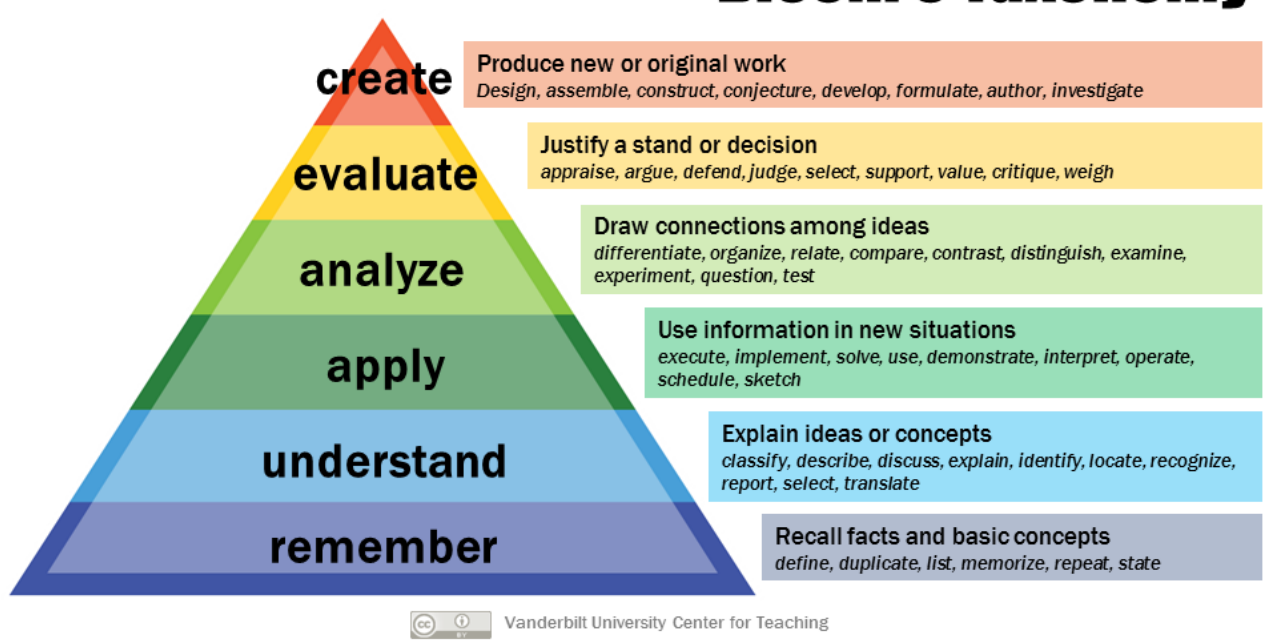

Figure 1: Bloom's taxonomy

\section{READINGS AND OTHER COURSE MATERIALS}

Assembling your own syllabus can be overwhelming, but there are a lot of resources out there that might help you out. Scholars from your field might post their syllabi on their personal websites, and there are repositories of syllabi, such as APSA and other professional associations. Many professors also share their syllabi on their social media, so make sure you follow them. These might all serve as great guides as you begin to think through your own syllabus. That advice along will get your far in terms of assembling your own reading list, but I'd like to add two additional points.

First, diversify your syllabus. It is important that your students see that scholarship is produced by people of all different backgrounds, so do not make your reading list a white brodeo. Several important resources exist that make that task relatively easy:

1. Women also know stuff

2. People of color also know stuff

\section{LGBT Scholar Network}

Second, don't be afraid to use other types of content, beyond books and articles. Since summer courses are condensed, I relied heavily on podcasts in my class, and students really loved it. 


\begin{tabular}{|c|c|c|c|}
\hline WEEK & DATE & TOPIC & THINGS TO READ/LISTEN TO/WATCH \\
\hline 1 & M MAY 7 & $\begin{array}{l}\text { Introductions; How people } \\
\text { process information }\end{array}$ & $\begin{array}{l}\text { 미 Flynn, Nyhan \& Reifler } \\
\text { 미 Patterson } \\
\text { gulia Galef's TED Talk } \\
\text { 의 Hidden Brain Podcast Ep. } 64 \\
\text { 의 You are not so smart Podcast Ep. } \\
94\end{array}$ \\
\hline
\end{tabular}

Figure 2: A screenshot of my syllabus. You can access the full document here.

Podcasts and videos are great for many reasons. Many students grew up with YouTube and podcasts, so that kind of medium is just natural to them. It is also convenient, since you can listen to a podcast during your commute, for example. Lastly, the podcast universe is so large at this point, and features great titles that examine many different scientific topics in great depth, including interviews with scholars, description of their works and findings. Some titles to consider include: Hidden Brain, You are not so smart, HKS's PolicyCast, Political Research Digest, The Ezra Klein Show, SSN's No Jargon, Freakonomics, HKS's Schorenstein Center's Media and Politics Podcast, Whistlestop, New Books in Political Science, Rationally Speaking, Inquiring Minds, Planet Money, and many others. Trust me, your students will love that.

\section{ASSIGNMENTS AND TESTS}

Deciding on what kinds of assignments to require is a difficult task. You should view the assignments as a vehicle through which you will animate the course objectives. In that sense, the assignments and other forms of assessment should all reflect your teaching goals for a given class.

Context of the course matters as well. During a normal length semester, it might make sense to assign a proper length research paper. However, in a condensed summer term, such an assignment might not be optimal. My personal preference is making students write frequently. Writing short response papers and memos is the kind of writing that many of them will do in a professional setting once they're done with their degrees, so practicing communicating an argument in a clear and structured way is a very useful skill for them to develop. In the summer of 2018, I have assigned six brief (two page) papers. For each one, I stated the topic of the paper clearly, so that the students had to write on a given topic, frequently responding to a particular question I would pose to them. A key feature of such assignments should be the clarity of your assessment and providing students with a clear set of expectations of what 
do you expect from the paper and why.

Personally, I am not a fan of midterms, exams, and quizzes. I don't see much pedagogical value in them, and instead prefer students to learn by doing and apply their acquired knowledge of the given subject this way. However, you might be bound by departmental rules to issue a final exam, for example, and you should always check to make sure that you abide by the rules of your department. Sometimes, you might have to rely on tests and quizzes for logistical reasons. For example, it might be impossible to grade research length papers from 80 students in one week that you have to submit the grades. In such scenarios, without grading help, you might have to rely on a final exam.

Something to consider is to experiment with assignment format. Your students will come from a variety of backgrounds and will have many different skills, like video editing, or being Photoshop wizards. Expressing their acquired knowledge using these skills tends to get them much more excited than writing a paper, and you can use different assignment formats to tap into their enthusiasm.

For example, in the summer of 2017 , I gave the students a fair amount of freedom to choose the medium through which to submit their final project. They had an option of writing a memo, producing an infographic, or making a video on the subject of fake news. The enthusiasm most students exhibited about this assignment blew me away, as did the quality of their work. One student produced a short film, with help from his friends. Another put together a 10 minute video explaining fake news and utilizing news clips from a variety of sources. Many others chose to put together infographics and booklets on the topic. The results were amazing and several students approached me after to say how fun the project was. If you consider something like that, it is important to set clear expectations for each medium and let students know that simply because they're not writing the paper, the bar is somehow not set lower for the quality of the product they need to submit.

In the summer of 2018 , the final assignment was a group project, working in groups of 4-5 students. The most difficult consideration was avoiding the common problem of free riding in group work.

To circumvent this issue, I decided to make $25 \%$ of everyone's grade be a reflection of the confidential assessment of each group member by all the other group members. For that purpose, I created a group member evaluation form, and required each student to submit this form to me personally. My worry was that each student will just give everyone else As, so I told them that I might ask them for justification for each 
classical_art_memes

\section{when you didn't do anything for the group project but still get an $\mathrm{A}+$}

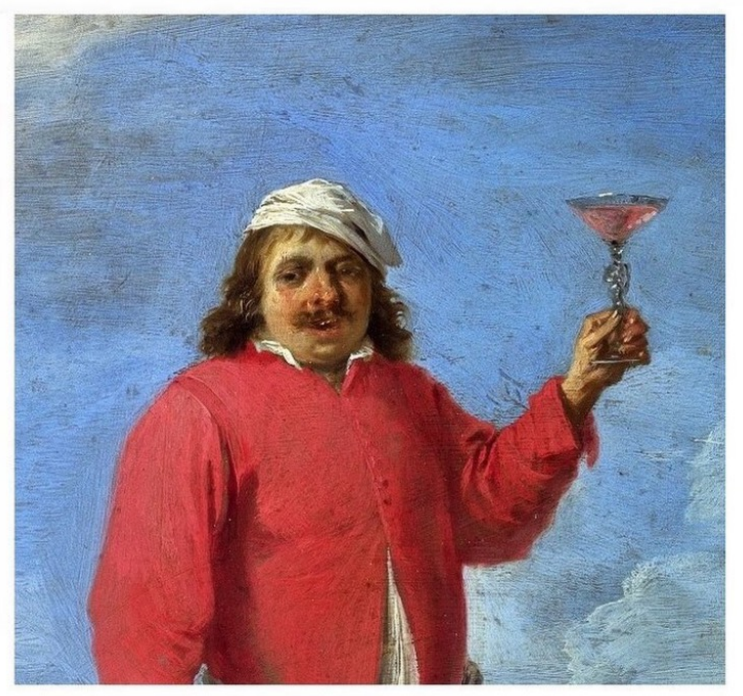

Figure 3: A common problem with group work

component of their evaluation. However, students were surprisingly frank and honest in their assessments, and I found that grading approach to work quite well.

The group project itself was also interesting. My goal was to have students gather and analyze real world data to answer a question to the problem - do we live in informational echo chambers? I took inspiration from Matthew Salganik at Princeton. The project involved 10 days of data collection on Twitter or Facebook, analyzing the data as a group, and then producing a research report. You can see more about the assignment here.

I also asked the students to fill out brief surveys once a week using Qualtrics. I used those surveys as mini assignments, and would use their content to fuel class discussion. The topics I asked for ranged from asking students about the news sources that they consume and other basic questions to their opinions on arguments in the literature. I would also use the surveys to demonstrate basic concepts to them. For example, one week, I split the students randomly into two groups. Both groups are 
asked about the Most Important Problem, but one of them has to read a brief article about climate change and it's perils. Every time, the group that sees the article rates climate change as much more important than the other group. I also replicate some classic framing effects studies on them. Students are always blown away that this worked on them and it makes for an interesting class discussion.

\section{LECTURES}

Standing in front of the classroom and lecturing for an hour is not an effective way to disseminate knowledge. That problem gets magnified in the summer when the courses are frequently on a condensed schedule, and each class lasts three hours.

You should absolutely not plan on lecturing for longer than 20 minutes. Instead, think of the class in terms of chunks of time, 15-20 minutes each. Make sure you change the mode of delivery frequently, since you're pushing the attention span by going longer than that.

I tried to follow a similar format in each class. I would start by asking for any questions and have a brief discussion with students about current events and how we can tie them to the course materials. Then, I relied on five things:

1. Lecture - I would talk about something, using my slides, for 15-20 mins

2. Videos - I would show students brief videos that were an example of a concept or phenomenon we were talking about, which included TED talks, online clips from sites such as Vox, various news programs, and documentaries

3. Group work - I would put students together in groups of 3-5 students (I find that size optimal) and make them produce something as a group: either an answer to a specific question, a definition of something, an argument in favor/against a specific position

4. Class discussion - Class discussion, on it's own, would rarely happen beyond the participation of the few students who always participate. But I found that Group discussion is usually a great jump off point to class discussion, where students already spend 15-20 minutes thinking about something and talking it through, and therefore are much more likely to engage

5. Review - I would end every lecture with a review. I would use tools such as Learning Catalytics to ask students a few, pre-prepared questions about the lecture and then use that to immediately discuss their answers, focusing on why the right answe is right but also discussing why specific answers are wrong 
I usually track attendance and participation manually, however, for the sake of attendance, a tool like Learning Catalytics is also very effective. It's always great to browse the IT/Learning Technology website of your university as you design your course, to discover what tools are available to you as an instructor and actually use them. They frequently make your life easier and make your class more interactive and fun.

\section{COMMUNICATION}

I am not a big fan of email. It is ineffective as a mode of communication between more than two people, messages get lost, and your already flooded inbox only get's more flooded. For the past two times that I taught, I used different messaging software in place of email and was very satisfied with the end result.

My software of choice is Slack. It is free, offers integrations with other applications that I use in the classroom, such as Dropbox, as well as other software to schedule meetings, etc. Most importantly, it is an efficient way to communicate. You can chat as a whole class, or privately in smaller groups, or individually. That way, if a student asks a question that others would likely be interested in, everyone can see my answer. And when someone who didn't read the syllabus carefully enough has a question, another student might quickly jump in with a response. Another benefit of software like Slack is that they have a great set of desktop and mobile apps developed, for any platform, so that students can get connected with the course on their phones if they want. The added benefit of Slack is that it slightly declutters your mailbox.

\section{PROBLEM SOLVING}

One of my worries before I taught for the first time was dealing with students who argued about their grade. I feared these confrontations. But after teaching, I realize that a lot of these discussions only come up when you, as an instructor, have not set clear enough expectations for a given assignment and did not provide clear enough feedback on student's work. Right from the beginning, however, I tell my class that if they feel like the grade they received does not reflect the quality of their work, I am open to hearing them out. My personal process involves the student writing me a one page memo describing their reasoning why they feel that their grade is too low. I then reevaluate the assignment. I make it clear, however, that the reevaluation might result in a grade going up or down. Sometimes the students make a compelling case and I change the grade, and sometimes the student shows me that I made a mistake and missed something in their work. Either way, you should always own up to your 
mistakes and show the students that you are open to reasonable dialogue and willing to own up when you mess up.

\section{WHAT ELSE TO PUT ON THE SYLLABUS?}

You should always check with your department what language you have to include on your syllabus. Frequently, there is standardized text you have to include about academic integrity and plagiarism, for example. If it is not required, you should still include your expectations of academic integrity and a definition of what constitutes plagiarism.

Personally, I also include links to counseling and mental health resources available to students. Many of them face problems in their private life that you are not aware of, and they are struggling with them unaware that most universities offer resources to help them deal with their issues. Pointing them out might help some of your students and it doesn't cost you anything to have that information easily accessible on the syllabus, and it might make a real difference in someone's life. 